\title{
Comparative outcomes of peripheral nerve blocks versus general anesthesia for hip fractures in geriatric Chinese patients
}

This article was published in the following Dove Press journal:

Patient Preference and Adherence

7 May 2014

Number of times this article has been viewed

\author{
Jun Le Liu',* \\ Xiao Lin Wangl,* \\ Mao Wei Gongl,* \\ Hai Xing $\mathrm{Mai}^{2}$ \\ Shu Jun Pei' \\ Wei Xiu Yuan' \\ Hong Zhang'
}

'Anesthesia and Operation Center, Chinese People's Liberation Army General Hospital and Medical School of Chinese People's Liberation Army, Beijing, People's Republic of China; 2Department of Urology, Affiliated Hospital of Academy of Military Medical Sciences, Beijing, People's Republic of China

*These authors contributed equally to this work
Correspondence: Hong Zhang Anesthesia and Operation Center, Chinese People's Liberation Army General Hospital, Fuxing Road 28th, Beijing, People's Republic of China $\mathrm{Tel}+86106693805$ I

Fax +86 I0 $8827 \quad$ I427

Email mazuimao30I@sina.cn
Background: Geriatric patients undergoing hemiarthroplasty for hip fractures have unacceptably high rates of postoperative complications and mortality. Whether anesthesia type can affect the outcomes has still been inconclusive.

Objectives: We compared general anesthesia (GA) and peripheral nerve blocks (PNBs) on postoperative complications and mortality in elderly patients with femoral neck fractures (FNF) undergoing hemiarthroplasty.

Materials and methods: This retrospective study involved data collection from an electronic database. Two hundred and seventeen patients underwent hemiarthroplasty for FNF between January 2008 and December 2012 at the Chinese People's Liberation Army General Hospital. Data on mortality within in-hospital, 30-day, and 1-year, complications, comorbidities, blood loss and transfusion, operative time, postoperative hospital length of stay, intensive care unit admission, and hospital charge were collected and analyzed. Univariate and multivariate Cox regression analyses of all variables were used for 30-day and 1-year mortality.

Results: Seventy-two patients receiving GA and 145 receiving PNBs were eventually submitted and analyzed. Mortality was $6.9 \%, 14.7 \%$, and $23.5 \%$ at in-hospital, 30-day, and 1-year, respectively postoperatively, while mortality and cardiovascular complications did not differ between the two anesthetic techniques. Preoperative comorbidities and intraoperative parameters were not statistically different except that patients receiving GA were more likely to have dementia $\left(\chi^{2}=10.45, P=0.001\right)$. The most common complications were acute cardiovascular events, electrolyte disturbances, and delirium. Postoperative acute respiratory events and hypoxemia both were also common, but no differences were found between groups $\left(\chi^{2}=0.68, P=0.410 ; \chi^{2}=3.42\right.$, $P=0.065$, respectively). Key factors negatively influencing mortality included: age, male gender, American Society of Anesthesiologists status, dementia, perioperative cardiovascular events and respiratory events, postoperative stroke, myocardial infarction, and hypoxia.

Conclusion: Mortality and postoperative complications are not statistically significantly different between PNBs and GA among eldery patients undergoing hemiarthroplasty for FNF.

Keywords: femoral neck fractures, elderly, mortality, postoperative complications

\section{Introduction}

Hip fractures are a global public health problem, occurring 1.6 million times worldwide in 1990, and their incidence is seeing an increasing trend in many countries across the globe partly due to an increase in the average life expectancy, and the increasing incidence of osteoporosis. ${ }^{1,2}$ After indicated surgical treatment, hip fracture patients experience high rates of morbidity, mortality, and disability, with approximately $5 \%$ dying during hospitalization and 10\% dying within 30 days. ${ }^{3,4}$ These unfortunate outcomes are challenging for perioperative clinicians, including anesthesiologists. 
The choice of anesthesia for this surgery is still an issue of continuing debate. Epidural anesthesia (EA), peripheral nerve blocks (PNBs), or general anesthesia (GA) are suitable for surgery in fragile patients. The first article on the assessment of anesthetic types was published in $1936 .{ }^{5}$ Since then, there have been many trials, observational studies, reviews, meta-analyses, and systematic reviews focusing on this point. ${ }^{6-8}$ In 2000 , Rodgers et al showed that the use of neuraxial techniques can result in a decrease in mortality and several complications. ${ }^{7}$ However, they were unable to draw conclusions on the validity of these findings to specific surgical procedures or patient populations. In addition, many of these studies are now approximately 20 years old. Thus, it has been difficult to draw conclusions regarding the effects of anesthesia choice on the outcomes for hip surgery.

With the development of ultrasonographic imaging and neurostimulation technology, more and more anesthesiologists have tended to select PNBs for lower limb surgery. PNB with propofol sedation is a sophisticated technique and is generally implemented in our hospital. This technique is not merely regional anesthesia or GA but a combination of the two, which administers sparing narcotic, propofol sedation with or without a oropharyngeal airway or laryngeal mask. Perioperative hemodynamic stability and improved postoperative analgesia make it more suitable for fragile patients with serious comorbidities.

In our department, anesthesiologists select the anesthesia style based on their preference and expertise, as well as the patients' general condition. For example, patients with cognitive dysfunction who can't communicate normally always receive $\mathrm{GA}$, and those patients with respiratory malfunction receive $\mathrm{PNBs}$ preventing from mechanical ventilation and inhaled gas, which can damage the respiratory system.

We therefore decided to investigate a population with femoral neck fractures (FNF) undergoing hemiarthroplasty in our hospital, to compare the effectiveness of GA and PNBs for postoperative complications and mortality. Our primary outcome is mortality at in-hospital, 30-day, and 1-year postoperatively. The secondary outcomes are major postoperative complications. This retrospective study may focus on the investigation of anesthetic factors influencing mortality and postoperative complications in a cohort of Chinese patients in our hospital.

\section{Materials and methods}

\section{Data source}

We explored postoperative mortality and complications in elderly patients undergoing urgent hemiarthroplasty for FNF who received GA or PNBs at the Chinese People's Liberation Army General Hospital from January 2008 to December 2012. The electronic database includes discharge records for all patients treated in the hospital and contains information on patient demographics, preoperative comorbidities, postoperative complications, anesthetic type, and in-hospital mortality. Thirty-day and 1-year mortality after surgery were recorded by a telephone interview or mail.

To create the cohort of patients aged 65 years or more, we selected all discharges with a principal or secondary diagnosis code for FNF, including pathologic fractures and traumas. To restrict our sample, we excluded patients who were diagnosed with multiple traumas and those who underwent a secondary surgical procedure during their hospital stay. To eliminate the influence of the operation and anesthesia types, patients who had undergone internal fixation ( $n=39)$, total hip arthroplasty $(n=68)$, or no surgery $(n=28)$ were excluded, and patients who had received EA ( $n=113)$ were also excluded. Finally, the remaining 217 subjects for hemiarthroplasty who received GA or PNBs were completed and used for further analysis (Figure 1).

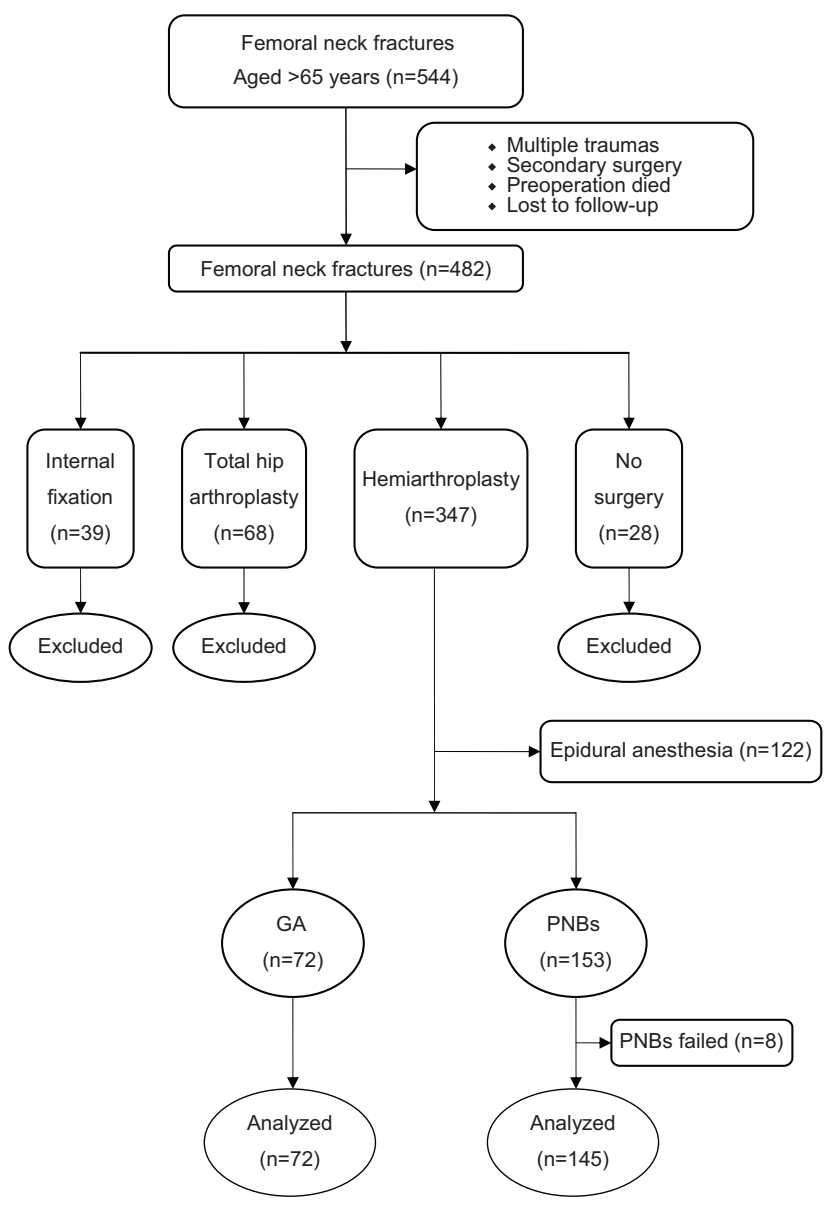

Figure I Flowchart showing patient enrollment and analysis. Abbreviations: GA, general anesthesia; PNBs, peripheral nerve blocks. 


\section{Anesthesia management}

Patients who received GA were routinely induced with midazolam, sufentanil, etomidate, and rocuronium, followed by laryngeal mask airway insertion and mechanical ventilation. Anesthesia was maintained with remifentanil and propofol with $60 \%$ oxygen. Infusion rates of propofol and remifentanil varied according to clinical judgment.

PNBs procedure was described in detail in our previous study. ${ }^{9}$ Briefly, midazolam and sufentanil were titrated to provide sufficient sedation before nerve block insertion. Supplemental oxygen ( $5 \mathrm{~L} /$ minute) was administered using a face mask. After sterile preparation and draping, the nerve blocks were administered using a 21-gauge, $100 \mathrm{~mm}$ nerve block needle (Stimuplex A ${ }^{\circledR}$; B. Braun Melsungen AG, Melsungen, Germany) under nerve stimulator guidance. A posterior approach to lumbar plexus block was performed with patients in the lateral decubitus position. After a quadriceps muscle response had been identified with nerve stimulator settings at $2 \mathrm{~Hz}$ frequency and current at $0.3-0.5 \mathrm{~mA}$, $20-30 \mathrm{~mL}$ of $0.30 \%$ ropivacaine was injected in divided doses. Sciatic nerve block was performed in the same position after a twitch of the hamstring, soleus, foot, or toes, had been elicited using a similar current, and $15-20 \mathrm{~mL}$ of $0.30 \%$ ropivacaine was injected. Sensory and motor blocks on the operated limb were evaluated until achievement of adequate nerve block to allow surgery. Sedation during surgery was provided by propofol with light sleep, ventilating spontaneously with a oropharynx parichnos or mechanically with a laryngeal mask. Supplemental analgesia with 5-10 $\mu \mathrm{g}$ sufentanil was administered if required.

\section{Surgical intervention}

All the operations were performed by two orthopedic surgeons (PFT and QZ) experienced in the procedure using a modified Hardinge anterolateral approach, with the patients in the lateral decubitus position..$^{10}$ All patients were given low-molecular-weight heparin calcium (Fraxiparine ${ }^{\circledR}$; GlaxoSmithKline, London, UK) preoperatively and for at least 10 days postoperatively, although this was interrupted from preoperative 1 day to 12 hours after surgery. Ceftriaxone-Na (Rocephin $^{\circledR} ; 1.0$ g; F. Hoffmann-La Roche Ltd., Basel, Switzerland), was given 30 minutes preoperatively, followed by two additional doses during the first 72 hours.

\section{Assessment and follow-up}

The primary outcome was in-hospital, 30-day, and 1-year mortality after surgery. The secondary outcomes are postoperative complications. The following general complications include: acute cardiovascular events, including myocardial infarction; acute respiratory events; stroke; delirium; electrolyte disturbances; hypoxemia; deep wound infection; and deep vein thrombosis/pulmonary embolus. We also examined the following data: waiting time to operation; duration of operation; postoperative hospital length of stay (PLOS); intensive care unit (ICU) admission; hospital charges; and blood loss and transfusion.

\section{Statistical analysis}

For continuous parameters, Student's $t$-tests were used to test for differences between groups, and chi-square statistics were used to detect differences for discontinuous parameters, including in-hospital mortality. Univariate and multivariate Cox regression analysis of all variables were used for 30-day and 1-year mortality after surgery. The significance level for all statistical tests was set at 5\% $(P<0.05)$. Data were coded and stored in Microsoft Excel (2007; Redmond, WA, USA) and analyzed with the statistical program SPSS (v17.0; IBM Corporation, Armonk, NY, USA).

\section{Results \\ Demographics}

During a 5-year period, 217 senior patients who had undergone hemiarthroplasty were eventually included in the analysis. The mean age was 79.8 years (range 65-103 years). Statistical analysis comparing patient characteristics between GA and PNBs groups is summarized in Table 1 and no statistically significant findings were made. Most of the patients were female $(151 / 217 ; 69.6 \%)$. The results for intraoperative fluid, PLOS, hospital charges, ICU admission, duration of operation, waiting time to operation, and blood loss and transfusion are presented in Table 2 . There were no statistically significant differences between the two anesthetic techniques.

\section{Mortality}

Mortality was $6.9 \%, 14.7 \%$, and $23.5 \%$ at in-hospital, 30-day, and 1-year postoperatively, and no statistically significant differences were found between the two groups. In-hospital mortality was slightly lower in the GA group $(9.7 \%$, $7 / 72)$ when compared to the PNBs group $(5.5 \%, 8 / 145)$. However, this did not reach statistical significance $\left(\chi^{2}=1.32\right.$; $P=0.250)$.

\section{Postoperative complications}

Sixty-eight patients (31.3\%) had one postoperative complication; 51 (23.5\%) had two, and 27 (14.3\%) had three or more complications. Table 3 shows the incidence of postoperative 
Table I Comparison of the demographics of 217 elderly patients between the GA and PNBs groups

\begin{tabular}{|c|c|c|c|c|c|}
\hline & $\begin{array}{l}\text { Total } \\
(n=217)\end{array}$ & $\begin{array}{l}\text { GA group } \\
(n=72)\end{array}$ & $\begin{array}{l}\text { PNBs group } \\
(n=\mid 45)\end{array}$ & $\chi^{2}$ or $95 \% \mathrm{Cl}$ & $P$-value \\
\hline Female* & I5I (69.6\%) & $5 \mathrm{I}(70.8 \%)$ & $100(69.0 \%)$ & 0.08 & 0.778 \\
\hline Age $\left(\right.$ years) ${ }^{\dagger}$ & $79.8 \pm 6.6$ & $78.8 \pm 5.6$ & $80.1 \pm 7.0$ & -3.16 to -0.56 & 0.169 \\
\hline Weight $(\mathrm{kg})^{\dagger}$ & $58.3 \pm \mathrm{II} .4$ & $57.4 \pm 9.3$ & $58.8 \pm 12.3$ & -4.60 to 1.86 & 0.404 \\
\hline Height $(\mathrm{cm})^{\dagger}$ & $162.1 \pm 7.5$ & $161.9 \pm 7.2$ & $161.2 \pm 7.7$ & -2.49 to 1.80 & 0.751 \\
\hline BMI $\left(\mathrm{kg} / \mathrm{m}^{2}\right)^{*}$ & $22.1 \pm 3.5$ & $21.8 \pm 2.8$ & $22.8 \pm 3.9$ & 148.26 & 0.455 \\
\hline Operation site (left)* & 109 (50.2\%) & 37 (5I.4\%) & $72(49.7 \%)$ & 0.06 & 0.810 \\
\hline ASA status* & & & & 2.60 & 0.273 \\
\hline 2 & 77 (35.5\%) & $25(34.7 \%)$ & $52(35.9 \%)$ & & \\
\hline 3 & 99 (45.6\%) & 35 (48.6\%) & $64(44.1 \%)$ & & \\
\hline 4 & $4 \mid$ (I8.9\%) & $12(16.7 \%)$ & 29 (20.0\%) & & \\
\hline
\end{tabular}

Notes: Data are presented as number (percentage), or ratio or mean \pm standard deviation; ${ }^{*} \chi^{2}$, test of independence; ttwo-tailed Student's $t$-test.

Abbreviations: ASA, American Society of Anesthesiologists; BMI, body mass index; Cl, confidence interval; GA, general anesthesia; PNBs, peripheral nerve blocks.

complications. The most common complications were acute cardiovascular events $(55 ; 25.3 \%)$, electrolyte disturbances $(51 ; 23.5 \%)$, and delirium $(50 ; 23.0 \%)$. The incidence of acute respiratory events was higher in the GA group than in the PNBs group, although no statistical significance was found $\left(\chi^{2}=0.68 ; P=0.410\right)$. Accordingly, there were similar tendencies for postoperative hypoxemia between the groups $\left(\chi^{2}=3.416 ; P=0.065\right)$.

\section{Preoperative comorbidities}

In our study, only 54 patients $(24.9 \%)$ had no preoperative comorbidity; 72 (33.2\%) had one, 57 (26.3\%) had two, and there were 34 (15.7\%) patients with three or more comorbidities. Table 3 lists the comorbidities recorded and their incidence between groups. The most common were cardiovascular diseases $(69 ; 31.8 \%)$, respiratory system diseases $(52 ; 24.0 \%)$, and diabetes $(51 ; 23.5 \%)$. Dementia was more common in the GA group than in the PNBs group $\left(\chi^{2}=10.45\right.$; $P=0.001$; Table 3 ).

\section{Preoperative and postoperative risk} factors for 30-day and I-year mortality

Table 4 shows univariate Cox regression analysis of all variables for mortality at 30 days and 1 year after surgery. Table 5 shows the results of the multivariate Cox regression analysis. The mortality of postoperative acute cardiovascular events was $41.8 \%(23 / 55)$ at 30 days (hazard ratio [HR]: $8.8,95 \%$ confidence interval $[\mathrm{CI}]: 5.0-18.9)$. The mortality at 1 -year was $80.0 \%$ (44/55; HR: 6.0, 95\% CI: 3.2-10.6). Of the patients who developed acute respiratory events, the mortality was 30.3\% (10/33; HR: 8.5 , 95\% CI: 6.6-13.1) at 30 days and 54.5\% (18/33; HR: 5.0, 95\% CI: 3.5-7.3) at 1 year.

The HRs for patients with respiratory system diseases after adjustments for age and sex are as follows: at 30 days (HR: 2.4, 95\% CI: 1.5-3.8), male (HR: 1.6, 95\% CI: 1.2-2.1), and dementia (HR: 2.0, 95\% CI: 1.5-3.7) (Table 5). Increasing age; male; American Society of Anesthesiologists (ASA) status; perioperative cardiovascular

Table 2 Intraoperative and postoperative data of the 217 subjects in the GA and PNBs groups

\begin{tabular}{|c|c|c|c|c|c|}
\hline & $\begin{array}{l}\text { Total } \\
(n=2 \mid 7)\end{array}$ & $\begin{array}{l}\text { GA group } \\
(n=72)\end{array}$ & $\begin{array}{l}\text { PNBs group } \\
(n=\mid 45)\end{array}$ & $\chi^{2}$ or $95 \% \mathrm{Cl}$ & $P$-value \\
\hline Waiting time to operation (days) ${ }^{\dagger}$ & $7.12 \pm 4.18$ & $6.83 \pm 4.34$ & $7.26 \pm 4.11$ & -1.62 to 0.76 & 0.478 \\
\hline PLOS (days) $)^{\dagger}$ & $8.87 \pm 4.65$ & $9.25 \pm 4.32$ & $8.68 \pm 4.81$ & -7.48 to 1.90 & 0.393 \\
\hline ICU (frequency)* & 38 (I7.5\%) & $9(12.5 \%)$ & $29(20 \%)$ & 1.87 & 0.171 \\
\hline Hospital charges $\left(10^{3} \mathrm{RMB}\right)^{\dagger}$ & $27.2 \pm 28.0$ & $23.6 \pm 15.6$ & $28.9 \pm 32.3$ & -1.32 to 2.30 & 0.194 \\
\hline Duration of operation (minutes) ${ }^{\dagger}$ & $105.9 \pm 32.4$ & $109 \pm 32.3$ & $104.3 \pm 32.5$ & -4.50 to $|3.9|$ & 0.315 \\
\hline Intraoperative fluid $(\mathrm{mL})^{\dagger}$ & $723 \pm 230$ & $720 \pm 282$ & $723 \pm 200$ & -67.88 to 62.92 & 0.941 \\
\hline Blood loss $(\mathrm{mL})^{\dagger}$ & $424 \pm 199$ & $429 \pm 199$ & $422 \pm 197$ & -49.17 to 63.17 & 0.806 \\
\hline \multicolumn{6}{|l|}{ Blood transfusion ${ }^{\dagger}$} \\
\hline Blood plasma (mL) & $253 \pm 204$ & $220 \pm 177$ & $262 \pm 219$ & -100.56 to 16.56 & 0.159 \\
\hline Red blood cells $(U)$ & $3.91 \pm 2.40$ & $3.8 I \pm 2.14$ & $3.98 \pm 2.55$ & -51.10 to 50.76 & 0.995 \\
\hline
\end{tabular}

Notes: Data are presented as mean \pm standard deviation or median; ${ }^{*} \chi^{2}$, test of independence; 'two-tailed Student's $t$-test.

Abbreviations: $\mathrm{Cl}$, confidence interval; GA, general anesthesia; ICU, intensive care unit; PLOS, postoperative hospital length of stay; PNBs, peripheral nerve blocks; RMB, renmenbi. 
Table 3 Preoperative comorbidities, postoperative complications, and mortality of 217 elderly patients in the GA and PNBs groups

\begin{tabular}{|c|c|c|c|c|c|}
\hline & $\begin{array}{l}\text { Total } \\
(n=2 \mid 7)\end{array}$ & $\begin{array}{l}\text { GA group } \\
(n=72)\end{array}$ & $\begin{array}{l}\text { PNBs group } \\
(n=\mid 45)\end{array}$ & $\chi^{2}$ & $P$-value \\
\hline \multicolumn{6}{|l|}{ Preoperative comorbidities } \\
\hline Cardiovascular diseases & 69 (31.8\%) & 21 (29.2\%) & $48(33.1 \%)$ & 0.34 & 0.558 \\
\hline Myocardial infarction & $18(8.3 \%)$ & $4(5.6 \%)$ & $14(9.7 \%)$ & 1.06 & 0.303 \\
\hline Respiratory system diseases & $52(24.0 \%)$ & $15(20.8 \%)$ & $37(25.5 \%)$ & 0.15 & 0.698 \\
\hline Diabetes & $5 \mathrm{I}(23.5 \%)$ & $16(22.2 \%)$ & $35(24.1 \%)$ & 0.10 & 0.754 \\
\hline Stroke & $48(22.1 \%)$ & $16(22.2 \%)$ & $32(22.1 \%)$ & 0.00 & 0.980 \\
\hline Dementia & $33(15.2 \%)$ & $19(26.4 \%)$ & $14(9.7 \%)$ & 10.45 & 0.001 \\
\hline Delirium & $38(17.5 \%)$ & $15(20.8 \%)$ & $23(15.9 \%)$ & 0.82 & 0.364 \\
\hline Renal disease & $22(10.1 \%)$ & $8(11.1 \%)$ & $14(9.7 \%)$ & 0.11 & 0.738 \\
\hline Electrolyte disturbances & $23(10.6 \%)$ & $9(12.5 \%)$ & $14(9.7 \%)$ & 0.41 & 0.522 \\
\hline Hypoxemia & $33(15.2 \%)$ & $13(18.1 \%)$ & $20(\mid 3.8 \%)$ & 0.68 & 0.410 \\
\hline Malignancy & 27 (I2.4\%) & $8(11.1 \%)$ & $19(13.1 \%)$ & 0.18 & 0.675 \\
\hline Number of patients with no comorbidities: & $54(24.9 \%)$ & $14(19.4 \%)$ & $40(27.6 \%)$ & 7.26 & 0.064 \\
\hline 1 & $72(33.2 \%)$ & $25(34.7 \%)$ & $47(32.4 \%)$ & & \\
\hline 2 & 57 (26.3\%) & $2 \mathrm{I}(29.2 \%)$ & $36(24.8 \%)$ & & \\
\hline$\geq 3$ & $34(15.7 \%)$ & $12(16.7 \%)$ & $22(15.2 \%)$ & & \\
\hline \multicolumn{6}{|l|}{ Postoperative complications } \\
\hline Acute cardiovascular events & 55 (25.3\%) & I8 (25.0\%) & $37(25.5 \%)$ & 0.01 & 0.934 \\
\hline Myocardial infarction & $8(3.7 \%)$ & $2(2.8 \%)$ & $6(4.1 \%)$ & 0.25 & 0.617 \\
\hline Acute respiratory events & $33(15.2 \%)$ & $13(18.1 \%)$ & $20(\mid 3.8 \%)$ & 0.68 & 0.410 \\
\hline Stroke & $9(4.1 \%)$ & $5(6.9 \%)$ & $4(2.8 \%)$ & 2.12 & 0.145 \\
\hline Delirium & $50(23.0 \%)$ & $18(25.0 \%)$ & $32(22.1 \%)$ & 0.23 & 0.629 \\
\hline $\mathrm{DVT} / \mathrm{PE}$ & II (5.1\%) & $5(6.9 \%)$ & $6(4.1 \%)$ & 0.79 & 0.375 \\
\hline Renal disorder & $37(17.1 \%)$ & II (I5.3\%) & $26(17.9 \%)$ & 0.24 & 0.625 \\
\hline Electrolyte disturbances & $5 I(23.5 \%)$ & $20(27.8 \%)$ & $3 \mathrm{I}(2 \mathrm{I} .4 \%)$ & 1.10 & 0.295 \\
\hline Anemia & $33(15.2 \%)$ & $12(16.7 \%)$ & $2 \mathrm{I}(\mathrm{I} 4.5 \%)$ & 0.18 & 0.673 \\
\hline Hypoxemia & $42(19.4 \%)$ & $19(26.4 \%)$ & $23(15.9 \%)$ & 3.42 & 0.065 \\
\hline Deep wound infection & $20(9.2 \%)$ & 7 (9.7\%) & $13(9.0 \%)$ & 0.03 & 0.856 \\
\hline Number of complications: & 67 (30.9\%) & $17(23.6 \%)$ & $50(34.5 \%)$ & 5.10 & 0.165 \\
\hline 1 & $68(31.3 \%)$ & $23(31.9 \%)$ & $45(31.0 \%)$ & & \\
\hline 2 & $5 I(23.5 \%)$ & $17(23.6 \%)$ & $34(23.5 \%)$ & & \\
\hline$\geq 3$ & 31 (14.3\%) & $15(20.8 \%)$ & $16(11.0 \%)$ & & \\
\hline \multicolumn{6}{|l|}{ Postoperative mortality } \\
\hline In-hospital & $15(6.9 \%)$ & $7(9.7 \%)$ & $8(5.5 \%)$ & 1.32 & 0.250 \\
\hline 30-day & $32(14.7 \%)$ & $12(16.7 \%)$ & $20(13.8 \%)$ & 0.32 & 0.574 \\
\hline I-year & $5 \mathrm{I}(23.5 \%)$ & $16(22.2 \%)$ & $35(24.1 \%)$ & 0.10 & 0.886 \\
\hline
\end{tabular}

Notes: Data are presented as number (percentage), or ratio or mean \pm standard deviation. Cardiovascular diseases include hypertension, coronary artery disease, and arrhythmia; respiratory system diseases include chronic obstructive pulmonary disease, asthma, pulmonary fibrosis, pneumonia, and chronic bronchitis; $\chi^{2}$, test of independence.

Abbreviations: DVT/PE, deep vein thrombosis/pulmonary embolus; GA, general anesthesia; PNBs, peripheral nerve blocks.

and respiratory events; postoperative stroke and hypoxia; three or more comorbidities; and postoperative complications were also key factors.

\section{Discussion}

Our study has shown $6.9 \%, 14.7 \%$, and $23.5 \%$ mortality at in-hospital, 30-day, and 1-year postoperatively in elderly patients who have undergone hemiarthroplasty for FNF. One hundred and fifty (69.1\%) patients had one or more postoperative complications. The most common were acute cardiovascular events, electrolyte disturbances, and delirium. There were no statistically significant differences between the two groups. In-hospital mortality was slightly lower in the GA group (9.7\%) when compared to the PNBs group (5.5\%). However, this did not reach statistical difference. Preoperative parameters were not statistically significantly different except that patients who received GA were more likely to have dementia. Increasing age; male; ASA status; perioperative cardiovascular and respiratory events; postoperative stroke and hypoxia; having three or more comorbidities; and postoperative complications are all risk factors for postoperative mortality.

The mortality at 30 days and 1 year after surgery is similar to that found in previous studies ${ }^{8,11}$ and no statistically significant differences were found between the two anesthetic techniques. However, few studies have 
Table 4 Univariate Cox regression analysis of all variables for mortality at 30 days and I year postoperatively: final step

\begin{tabular}{|c|c|c|}
\hline & 30-day mortality & I-year mortaily \\
\hline Male sex & $1.8(1.6 \text { to } 2.5)^{* *}$ & $1.6(1.2 \text { to } 3.2)^{* *}$ \\
\hline ICU admission & $1.8(1.2$ to 3.8$)$ & $1.3(0.8$ to 2.0$)$ \\
\hline$\geq 85$ years & $2.8(1.5 \text { to } 5.5)^{*}$ & $3.0(2.1 \text { to } 5.4)^{*}$ \\
\hline \multicolumn{3}{|l|}{ Preoperative comorbidities } \\
\hline Cardiovascular diseases & $1.7(1.2$ to 2.0$)$ & $1.3(\mathrm{I} . \mathrm{I} \text { to } \mathrm{I} .8)^{*}$ \\
\hline Diabetes & $1.2(0.9$ to 1.9$)$ & I.4 (I.I to I.7) \\
\hline Respiratory system diseases & $2.4(1.4 \text { to } 3.8)^{*}$ & $1.8(1.2 \text { to } 2.8)^{*}$ \\
\hline Stroke & I.3 (I.I to I.7) & I.I (0.9 to I.5) \\
\hline Dementia & $2.2(\mathrm{I} .4 \text { to } 4.8)^{*}$ & $2.5(2.1$ to 4.0$)$ \\
\hline Hypoxia & $3.6(1.5$ to 12.4$)$ & $1.9(0.8$ to 5.2$)$ \\
\hline Malignancy & $1.2(1.0$ to 2.0$)$ & 1.7 (I.4 to 2.9$)$ \\
\hline Comorbidities $\geq 3$ & $2.2(1.5 \text { to } 3.2)^{* *}$ & $2.5(2.2 \text { to } 3.7)^{* *}$ \\
\hline ASA $\geq$ III & $2.5(1.8 \text { to } 4.4)^{* *}$ & $3.8(2.6 \text { to } 5.8)^{* *}$ \\
\hline \multicolumn{3}{|c|}{ Postoperative complications } \\
\hline Acute cardiovascular events & $8.8(5.0 \text { to } 18.9)^{* *}$ & $6.0(3.2 \text { to } 10.6)^{* *}$ \\
\hline Myocardial infarction & 10.1 (3.3 to 36.7$)^{* *}$ & $8.4(2.0$ to 32.5$) * *$ \\
\hline Acute respiratory events & $8.5(6.6 \text { to I } 3.1)^{* *}$ & $5.0(3.5 \text { to } 7.3)^{* *}$ \\
\hline Stroke & $8.8(4.9 \text { to } 18.5)^{* *}$ & $5.6(3.4 \text { to } 9.7)^{*}$ \\
\hline Delirium & $2.0(1.2$ to 4.3$)$ & $1.6(0.9$ to 3.4$)$ \\
\hline DVT/PE & $1.9(1.1$ to 4.2$)$ & $2.3(1.7$ to 3.6$)$ \\
\hline Hypoxia & $3.6(1.9 \text { to } 8.8)^{*}$ & $2.4(1.3$ to 4.4$)$ \\
\hline Anemia & $0.9(0.6$ to 2.3$)$ & $1.6(0.9$ to 2.8$)$ \\
\hline Deep wound infection & $0.5(0.1$ to 4.8$)$ & I.2 (I.0 to 3.5$)$ \\
\hline$\geq 3$ complications & I 4.5 (8.9 to 19.9)** & $7.8(4.6 \text { to } 10.3)^{* *}$ \\
\hline
\end{tabular}

Notes: Data are hazard ratios ( $95 \%$ confidence intervals); $* * P<0.01 ; * P<0.05$

Abbreviations: ASA, American Society of Anesthesiologists; DVT/PE, deep vein thrombosis/pulmonary embolus; ICU, intensive care unit.

compared the outcomes between GA and PNBs in Chinese patients. Interestingly, male patients $(14 ; 21.2 \%)$ have a significantly higher mortality at 30 days than female patients $(18 ; 11.9 \%)$, who lived longer on average. ${ }^{12}$ Our results showed high mortality for patients who developed acute cardiovascular and respiratory events. Within 30 days after surgery, $41.8 \%(23 / 55)$ of patients with acute cardiovascular events and 30.3\% $(10 / 33)$ with acute respiratory events died, whereas only $9.8 \%(5 / 51)$ of patients with electrolyte disturbances died.

Table 5 Multivariate Cox regression analysis of variables for 30-day and I-year mortality

\begin{tabular}{|c|c|c|}
\hline & 30-day mortality & I-year mortality \\
\hline Male sex & $1.6(1.2 \text { to } 2.1)^{*}$ & I.8 (I.5 to 3.8$)^{* *}$ \\
\hline ICU admission & 2.0 (1.3 to 4.2$)$ & $1.3(0.9$ to 2.4$)$ \\
\hline$\geq 85$ years & $1.8(1.2 \text { to } 4.0)^{*}$ & $2.2(1.5 \text { to } 4.6)^{*}$ \\
\hline \multicolumn{3}{|l|}{ Preoperative comorbidities } \\
\hline Cardiovascular diseases & $0.9(0.7$ to I.3) & $1.2(0.9$ to 2.1$)$ \\
\hline Diabetes & I.I (0.8 to I.7) & $1.2(\mathrm{I} .0$ to $\mathrm{I} .7)$ \\
\hline Respiratory system diseases & $2.4(1.5 \text { to } 3.8)^{*}$ & $1.8(1.2 \text { to } 3.3)^{*}$ \\
\hline Stroke & 1.2 (0.9 to 1.9$)$ & I.I (0.9 to I.6) \\
\hline Dementia & $2.0(1.5$ to 3.7$)$ & $2.2(1.8$ to 4.0$)$ \\
\hline Hypoxia & $2.2(1.8 \text { to } 7.2)^{*}$ & $1.5(1.2 \text { to } 2.6)^{*}$ \\
\hline Malignancy & $1.3(\mathrm{I} . \mathrm{I} \text { to } 2.5)^{*}$ & $1.4(1.1 \text { to } 2.8)^{* *}$ \\
\hline \multicolumn{3}{|c|}{ Postoperative complications } \\
\hline Acute cardiovascular events & $5.8(4.5 \text { to } 1 \mathrm{I} .7)^{* *}$ & $4.6(3.0 \text { to } 9.8)^{* *}$ \\
\hline Myocardial infarction & $6.2(2.5 \text { to } 9.6)^{* *}$ & $3.8(2.2 \text { to } 6.1)^{* *}$ \\
\hline Acute respiratory events & $4.4(3.2 \text { to } 9.0)^{* *}$ & $3.5(3.0 \text { to } 6.8)^{* *}$ \\
\hline Stroke & $2.6(1.3 \text { to } 5.5)^{* *}$ & $3.0(2.3 \text { to } 6.2)^{*}$ \\
\hline Acute renal impairment & I.8 (0.8 to 3.3$)$ & $2.0(1.1$ to 3.4$)$ \\
\hline Hypoxia & 3.5 (1.9 to 6.4$)$ & 1.8 (1.3 to 2.8$)$ \\
\hline
\end{tabular}

Notes: Data are hazard ratios ( $95 \%$ confidence intervals); $* * P<0.01 ; * P<0.05$.

Abbreviation: ICU, intensive care unit. 
Forty-four $(80.0 \%)$ patients with acute cardiovascular events died within 1 year postoperatively.

Some of our patients with hip fractures are from outside the immediate vicinity of our district. Perhaps these patients were sicker at baseline than others with hip fractures who remained at the local hospitals. It is possible that the patients were transferred to us because they were "too sick" and therefore had a higher risk of early mortality.

One hundred and sixty-three patients (75.1\%) had one or more comorbidities on admission. The most common were cardiovascular diseases, respiratory system diseases, diabetes, and stroke. It appears that some patients with preoperative comorbidities did not have serious postoperative complications. Previous research has indicated that myocardial infarction, dementia, and respiratory system diseases result in a greater risk of postoperative complications and increased mortality. ${ }^{13,14}$ One in-hospital patient in the PNBs group had a myocardial infarction after surgery and died during their postoperative in-hospital stay, while a patient in the GA group suffered perioperative cardiac arrest and died in hospital, although both had been managed carefully and operated on successfully.

Thirty-three patients (15.2\%) in our study had dementia; these patients are thought to be more likely to have postoperative complications and higher mortality. ${ }^{15,16}$ The incidence of dementia was much higher in the GA group $(19 / 72 ; 26.4 \%)$ than in the PNBs group (14/145; 9.7\%; $P=0.001)$. "Mental deterioration in the elderly can be avoided by selecting regional rather than general anaesthesia." ${ }^{.16}$ Due to the importance of body posture during the PNBs procedure, many patients with dementia were not suited for this anesthetic type and had to receive GA in our data. Accordingly, lower mortality at in-hospital and 30-day postoperatively in the PNBs group could not be fully attributed to the anesthetic type.

The hypovolemia was poorly tolerated by the more fragile patients, even if the blood loss was less. A retrospective study of over 8,000 elderly patients with hip fractures found that perioperative transfusion had no influence on mortality in patients with hemoglobin concentrations $>80$ $\mathrm{g} / \mathrm{L},{ }^{17}$ although some other studies have shown that transfusion at higher hemoglobin concentrations for patients with known cardiac disease may be beneficial. ${ }^{18,19}$ The issue of whether a blood transfusion should be administered is still inconclusive in this fragile population.

Meanwhile, "persistent hypoxia may be present in all patients with hip fractures from the time of admission until up to several days postoperatively." ${ }^{20}$ In our study, 33 (15.2\%) patients were hypoxemic when the first arterial blood samples were drawn; of these, 27 patients (81.8\%) still had arterial oxygen pressure $<60 \mathrm{mmHg}$ postoperation. Futhermore, anemia, hypoxemia, and hypoproteinemia invariably occur concomitantly, which may be positively correlated to postoperative mortality. ${ }^{21,22}$ As such, an appropriate transfusion threshold would limit risk and optimize benefits in the elderly. Therefore, in our department, all patients are continually administered supplemental oxygen (3-5 L/minute) with a nasal catheter perioperatively. We recommend that the hemoglobin concentrations $<90 \mathrm{~g} / \mathrm{L}$ should be administered in fragile patients.

Electrolyte disturbances are common preoperation $(23 ; 10.6 \%)$ and during the first 3 days postoperatively (51; 23.5\%). Hypokalemia is the most common electrolyte abnormality and is intractable even if the patient is given potassium transvenously and via oral intake. Six patients $(11.8 \%)$ with postoperative electrolyte disturbances died within 30 days after surgery, but positive correlation of these deaths has not been confirmed.

Hip fracture patients are at high risk of delirium, with incidence ranging from $35 \%$ to $50 \% .{ }^{6,15,16}$ Some evidence has indicated that improved postoperative analgesia with PNBs could decrease the incidence of delirium. Unfortunately, our retrospective data did not include analgesic outcomes. The incidence of delirium was $25 \%$ (18) in the GA group and $22.1 \%$ (32) in the PNBs group; this difference was not statistically significant in our study $(P=0.629)$. However, the research demonstrates that risk of delirium in elderly patients prognosticates increasing PLOS and hospital charges.

The frequency of ICU admission in PNBs group is more than that in the GA group numerically ( $20 \%$ vs $12.5 \%$; $P=0.171$ ). Contrary to what might have been expected, we show that ICU admission is not positively associated with increased mortality at the observed time points. However, patients with ICU admission have higher hospital charges and longer PLOS.

No significant differences were found between the groups in our study regarding blood loss (GA vs PNBs; $429 \pm 199$ $\mathrm{mL}$ vs $422 \pm 197 \mathrm{~mL} ; P=0.806$ ) and blood transfusions. As in previous reports, ${ }^{23}$ blood loss may attribute to intraoperative blood pressure and surgical time. Unfortunately, we did not analyze blood pressure in these groups due to the limited records.

In our study, the interval time from trauma to surgery was long and some surgeries were delayed for up to 7 days. Empirical evidence has demonstrated that shortening surgery delay reduces complications, PLOS, and mortality. ${ }^{24-26}$ However, another study showed no significant difference in 
mortality between patients having early or delayed surgery. ${ }^{27}$ Some sicker patients received earlier surgery, nevertheless they did not have adequate physiologic reserves and remained under resuscitation. Hence, delaying surgery to adequately resuscitate patients and optimizing medical conditions do not worsen the outcomes.

To the subpopulation with hip fracture which administered no anticoagulation, deep vein thrombosis may be less frequent duration of hospital stay in RA than that in GA. ${ }^{28}$ In our department, all patients with lower limb surgery must be administered low-molecular-weight heparin, a prophylactic anticoagulant. We did not find a statistically significant difference in clinical thrombosis between the GA and PNBs groups $(P=0.658)$.

Regarding PLOS and hospital charges, there were no statistically significant differences between the two groups ( $P=0.631$ and $P=0.601$, respectively). The hospital charges, excluding procedural and equipment charges, are more dependent on the cost of presurgery comorbidities and postoperative complication care. However, the cost of hospitalization increased with a delay in surgery, PLOS, and ICU admission in our study.

With the development of anesthesiology and the theoretic improvement of anesthesiologists, anesthetic techniques are improving over time. In 2008, GA was applied in $45.7 \%$ of patients, and PNBs are applied in $14.3 \%$ of patients. By 2012, GA decreased to only $12.9 \%$, where PNBs sharply increased to $52.7 \%$. Furthermore, in 2008, patients weren't usually admitted to the ICU unless they presented serious complications, such as cardiac arrest, or acute cardiac or respiratory failure. Nowadays, our patients at high cardiac or respiratory risk are routinely admitted to the ICU during the first 1 or 2 days postoperatively. Thus, we did not observe higher mortality in the PNBs group, even though most of these patients are older.

There are recognized limitations to this study. Firstly, this study is retrospective and the use of an administrative database that might be subject to inaccuracies in coding and data collection could have influenced the results of the study. Some "atypical" complications are more prevalent in elderly patients, but the data were not recorded and analyzed. In addition, the database did not allow the authors to assess outcomes with respect to pain and intraoperative parameters. Secondly, the patients' status and anesthesiologists' favorites could have resulted in anesthesia selection bias. Thus, our existing data does not reflect the real mortality. In addition, our exclusion of patients who did not undergo surgery or who received EA might limit the generalizability of our results.
Finally, the small sample size and single center study make it difficult to appreciate statistically significant differences between groups.

\section{Conclusion}

Our study has shown that mortality and postoperative complications are not statistically significantly different between PNBs and GA among elderly patients who underwent hemiarthroplasty for FNF. Although patients who received PNBs are older, dementia was more frequently found in the GA group. In fact, perioperative comanagement of geriatric patients with hip fractures may be more important than the anesthesia type. Unfortunately, the team of multi-departments' management was not founded in our hospital.

\section{Author contributions}

JL Liu carried out the literature search and wrote the manuscript; XL Wang acquired the data, carried out statistical analysis, and followed up the subjects; MW Gong collected the data and drafted the manuscript; and HX Mai carried out statistical analysis and revising the manuscript critically for important intellectual content; WX Yuan was involved in designing the research and writing the manuscript; while SJ Pei was involved in interpreting data, critical revision, and followed up the subjects. H Zhang was responsible for the conception and management of the study and audited the study design, edited the manuscript, and acted as guarantor. All coauthors approved the version to be published finally and were accountable for the accuracy or integrity of the work.

\section{Acknowledgments}

The authors thank the many research staff involved in this study, especially, Pei Fu Tang, Professor and Director, Department of Orthopaedics, Chinese People's Liberation Army General Hospital, Beijing, People's Republic of China; Qun Zhang, Associate Professor, Department of Orthopaedics, Chinese People's Liberation Army General Hospital, Beijing, People's Republic of China. We also thank Zhi Li (Shanxi Medical University, Taiyuan, People's Republic of China) for his assistance in statistical analysis.

\section{Disclosure}

The authors report no conflicts of interest in this work.

\section{References}

1. Johnell O, Kanis JA. An estimate of the worldwide prevalence and disability associated with osteoporotic fractures. Osteoporos Int. 2006; 17(12):1726-1733. 
2. Brauer CA, Coca-Perraillon M, Cutler DM, Rosen AB. Incidence and mortality of hip fractures in the United States. JAMA. 2009; 302(14):1573-1579.

3. Roche JJ, Wenn RT, Sahota O, Moran CG. Effect of comorbidities and postoperative complications on mortality after hip fracture in elderly people: prospective observational cohort study. BMJ. 2005;331(7529):1374.

4. Radcliff TA, Henderson WG, Stoner TJ, Khuri SF, Dohm M, Hutt E. Patient risk factors, operative care, and outcomes among older community-dwelling male veterans with hip fracture. J Bone Joint Surg Am. 2008;90(1):34-42.

5. Nvgaard KK. Routine spinal anesthesia in a provincial hospital with comparative study postoperative complications following spinal and general ether anesthesia. Acta Chir Scand. 1938;78:379-446.

6. White SM, Griffiths R, Holloway J, Shannon A. Anaesthesia for proximal femoral fracture in the UK: first report from the NHS Hip Fracture Anaesthesia Network. Anaesthesia. 2010;65(3):243-248.

7. Rodgers A, Walker N, Schug S, et al. Reduction of postoperative mortality and morbidity with epidural or spinal anaesthesia: results from overview of randomised trials. BMJ. 2000;321(7275):1493.

8. O'Hara DA, Duff A, Berlin JA, et al. The effect of anesthetic technique on postoperative outcomes in hip fracture repair. Anesthesiology. 2000; 92(4):947-957.

9. Liu J, Yuan W, Wang X, et al. Peripheral nerve blocks versus general anesthesia for total knee replacement in elderly patients on the postoperative quality of recovery. Clin Interv Aging. 2014;9:341-350.

10. Hardinge K. The direct lateral approach to the hip. J Bone Joint Surg Br. 1982;64(1):17-19.

11. Urwin SC, Parker MJ, Griffiths R. General versus regional anaesthesia for hip fracture surgery: a meta-analysis of randomized trials. $\mathrm{Br} J$ Anaesth. 2000;84(4):450-455.

12. Sharma H, Vashishtha P, Sharma R. Gender differences in patients with hip fracture: a greater risk of morbidity and mortality in men. J Orthop Trauma. 2005;19(5):365-366; author reply 366.

13. Nettleman MD, Alsip J, Schrader M, Schulte M. Predictors of mortality after acute hip fracture. J Gen Intern Med. 1996;11(12):765-767.

14. Dirksen A, Kjøller E. Cardiac predictors of death after non-cardiac surgery evaluated by intention to treat. BMJ. 1988;297(6655):1011-1013.

15. Riis J, Lomholt B, Haxholdt $\mathrm{O}$, et al. Immediate and long-term mental recovery from general versus epidural anesthesia in elderly patients. Acta Anaesthesiol Scand. 1983;27(1):44-49.
16. Williams-Russo P, Sharrock NE, Mattis S, Szatrowski TP, Charlson ME Cognitive effects after epidural vs general anesthesia in older adults. A randomized trial. JAMA. 1995;274(1):44-50.

17. Carson JL, Duff A, Berlin JA, et al. Perioperative blood transfusion and postoperative mortality. JAMA. 1998;279(3):199-205.

18. Hogue CW Jr, Goodnough LT, Monk TG. Perioperative myocardial ischemic episodes are related to hematocrit level in patients undergoing radical prostatectomy. Transfusion. 1998;38(10):924-931.

19. Nelson AH, Fleisher LA, Rosenbaum SH. Relationship between postoperative anemia and cardiac morbidity in high-risk vascular patients in the intensive care unit. Crit Care Med. 1993;21(6):860-866.

20. Dyson A, Henderson AM, Chamley D, Campbell ID. An assessment of postoperative oxygen therapy in patients with fractured neck of femur. Anaesth Intensive Care. 1988;16(4):405-410.

21. Foss NB, Kristensen MT, Kehlet H. Anaemia impedes functional mobility after hip fracture surgery. Age Ageing. 2008;37(2):173-178.

22. Foss NB, Kristensen MT, Jensen PS, Palm H, Krasheninnikoff M, Kehlet $\mathrm{H}$. The effects of liberal versus restrictive transfusion thresholds on ambulation after hip fracture surgery. Transfusion. 2009;49(2): 227-234.

23. Mauermann WJ, Shilling AM, Zuo Z. A comparison of neuraxial block versus general anesthesia for elective total hip replacement: a metaanalysis. Anesthesia and analgesia. Oct 2006;103(4):1018-1025.

24. Petersen MB, Jørgensen HL, Hansen K, Duus BR. Factors affecting postoperative mortality of patients with displaced femoral neck fracture. Injury. 2006;37(8):705-711.

25. Sharma PT, Sieber FE, Zakriya KJ, et al. Recovery room delirium predicts postoperative delirium after hip-fracture repair. Anesth Analg. 2005;101(4):1215-1220, table of contents.

26. Morrison RS, Magaziner J, McLaughlin MA, et al. The impact of postoperative pain on outcomes following hip fracture. Pain. 2003;103(3): 303-311.

27. March LM, Chamberlain AC, Cameron ID, et al. How best to fix a broken hip. Fractured Neck of Femur Health Outcomes Project Team. Med J Aust. 1999;170(10):489-494.

28. Hole A, Terjesen T, Breivik H. Epidural versus general anaesthesia for total hip arthroplasty in elderly patients. Acta Anaesthesiol Scand. 1980;24(4):279-287.
Patient Preference and Adherence

\section{Publish your work in this journal}

Patient Preference and Adherence is an international, peer-reviewed, open access journal that focusing on the growing importance of patient preference and adherence throughout the therapeutic continuum. Patient satisfaction, acceptability, quality of life, compliance, persistence and their role in developing new therapeutic modalities and compounds to optimize

\section{Dovepress}

clinical outcomes for existing disease states are major areas of interest for the journal. This journal has been accepted for indexing on PubMed Central. The manuscript management system is completely online and includes a very quick and fair peer-review system, which is all easy to use. Visit http://www. dovepress.com/testimonials.php to read real quotes from published authors. 